\title{
Nurses' Involvement in HIV Policy Formulation in Nigerian Health Care System
}

\author{
Ekaete Francis Asuquo*, Josephine Bassey Etowa, Wendy A Gifford and Dave Holmes \\ School of Nursing, University of Ottawa, Ontario, Canada
}

\begin{abstract}
Background of study: Nigerian national policy on HIV stresses the need for the adoption of multi-sectoral and multi-disciplinary approach in policy formulation, with the health sector taking the lead. This calls for collaboration among the various stakeholders including nurses in policy development initiatives to ensure that diverse health care needs and disciplinary perspectives are captured in HIV health policies.
\end{abstract}

Purpose: This paper will present the findings of a recent study which examined nurse's involvement in policy development in the context of mother-to-child transmission (MTCT) of HIV in Nigeria.

Methodology: A qualitative case study design under the guiding tenets of critical social and power theories. The research is a single case study of one state with embedded units. Thirty nurse-leaders from the various embedded units were recruited through purposive and snowball sampling technique. Semi-structured in-depth interviews and document reviews were used for data collection. Focus group discussions were used as a form of member-checking and also to generate data. Data was analysed using thematic analysis.

Results: This paper focuses on the major themes that emerged from the study as well as highlight specific interplay of power dynamics in the health care system which hinders nurse's involvement in policy formulation.

Conclusion: The paper concludes with some of the lessons learnt in the study and proffer suggestions for effective integration of nurses into policy arena. It suggests the need for a broad-based educational curriculum which will incorporate strategies to build nurses capacity for leadership and policy development in nursing training schools.

Keywords: Nurses; HIV; PMTCT policy; Power dynamics; Nigeria

\section{Introduction}

HIV epidemic had prompted a critical re-appraisal of how health care stakeholders plan and deliver care to those affected and infected by the disease. These include the re-assessment of the policy formulation process and the identification of implementation bottlenecks. In Nigeria, national policy on HIV stresses the need for the adoption of multisectoral and multi-disciplinary approach in policy formulation, as the foundation for elimination of HIV from mother-to-child. According to Sturke et al. until this approach (multi-sectoral and multi-disciplinary) in policy is adopted, implementations of prevention of mother-to-child HIV transmission (PMTCT) interventions in low and middle income countries with high rate of mother to child HIV transmission may be difficult to achieve [1].

In most African countries, nurses' make-up significant number $(80 \%)$ of health care workforce $[2,3]$. Their contribution to alleviating disease burden through disease prevention, early detection/ care and health promotion which aids the improvement of health outcomes is well known. According to WHO, nurse's contributions remain crucial in attaining targeted health outcomes of individuals, families, communities as well as millennium development goals [4]. With HIV pandemic, International Center for AIDs care and Treatment Programs affirmed that without nurses it would be impossible to achieved maximum HIV response [5]. It became necessary to expand the role of nurses through task shifting; a concept which acts as the vanguard for the renaissance to PMTCT services in sub-Saharan Africa [6-8]. However, in spite of their contribution, nurses are not recognized as key stakeholders at the health policy forums [4].

The need to reposition nursing profession so that nurses are situated at the center of both health services and the health care planning becomes imperative. Their centrality would enhance effective policy formulation and implementation especially in Nigeria where PMTCT coverage has remained low [9]. According to Phaladze, nurse's involvement in policy formulation and policy implementation are pivotal to the success or failure of the HIV/AIDS programs [10]. This view is supported by American Institute of Medicine and WHO who advocated for active engagement and leadership of nurses at every level of health policy/programme development and decision-making [4]. Similarly, International Council of Nurses strongly emphasised the significance of nurses' contribution to health care system planning and their participation in policy development as the panacea to effective health care outcome.

Their marginal representation in health decision-making roles in some low and middle-income countries (LMICs) has been reported in many studies $[2-4,11]$. This limited representation has constrained the ability for nursing-relevant input into policy issues to overcome PMTCT implementation constraints. According to Shariff, there are certain complex factors that limit nurses' participation in health policy fora, such as poor valuing of nurse's contributions, lack of knowledge, skills and support and lack of enabling structures [11]. Ditlopo et al. added that nurses occupy lower position in the hierarchy of health care system, and with a top down policy flow pattern utilized, nurse's

*Corresponding author: Ekaete Francis Asuquo RN, PhD, School of Nursing University of Ottawa, Ontario, Canada, Tel: 6138900384; E-mail: easuq095@uttowa.ca

Received May 19, 2016; Accepted June 10, 2016; Published June 17, 2016

Citation: Asuquo EF, Etowa JB, Gifford WA, Holmes D (2016) Nurses' Involvement in HIV Policy Formulation in Nigerian Health Care System. J AIDS Clin Res 7: 589. doi:10.4172/2155-6113.1000589

Copyright: (c) 2016 Asuquo EF, et al. This is an open-access article distributed under the terms of the Creative Commons Attribution License, which permits unrestricted use, distribution, and reproduction in any medium, provided the original author and source are credited. 
involvement in policy is not possible [12]. However, Abood identified lack of political skills and nurse's unwillingness to leave their comfort zone [13]. Ugochukwu et al. asserted that it is common for African politicians, policy-makers and health administrators to acknowledge that the nursing profession is integral to the success of the health sector [14]. However, these health stakeholders fail to back up this assertion with supportive policies that permit maximum performance of nurses' output, such as engagement in all levels of policy development. Rather, these stakeholders encourage structures that inhibit the development of potential leaders in the nursing profession for these countries. Therefore, there is need for a more interdisciplinary approach in health policy development process with involvement of all related stakeholders including nurses.

This paper presents the results of a recent study on nurses' involvement in PMTCT health policy development, and the resources available to build their capacity to engage in policy formulation fora.

\section{Research Design}

The study is a qualitative case study design, informed by Critical social theory (CST) and Power theory. CST is used to enhance critique, conscientization (subjective appraisal of individualized contributions towards PMTCT policies), dialogue, and action for emancipation from barriers in the health care system. Power theory exposes power inequities in the study contexts, illuminates the hierarchical systems of domination and subordination that are often embedded in societal and organizational structures.

\section{Nigeria health care system}

There are basically three-tier levels of Health Care System (HCS) in Nigeria namely: primary, secondary and tertiary care systems. The Federal Government provides for tertiary health care facilities, the State ministries of Health for the secondary level of care, while local governments provide for primary health services. The National Agency for the Control of AIDS (NACA) coordinates the overall national response to HIV/AIDS. The State Agency for the Control of AIDS (SACA) and the Local Government Agency for the Control of AIDS (LACA) are the coordinating bodies at the sub-national levels. The Ministry of Health and Local Government Councils serve as the focal point, providing leadership and policy direction for all health programs in the state and local government areas respectively.

Cross River State HCS is in line with the national HCS. To obtain an in-depth understanding of nurses' involvement in PMTCT policy formulation, this study was considered as a single case with embedded units. The case is Cross River State, one of 36 states in Nigeria, divided into 18 local government areas with six local government areas making up a zone. The embedded units were health establishments, nursing associations, HIV/AIDS support organizations, and health care institutions representing different bodies directly or indirectly affiliated with the formulation of health care policies in Cross River State. The state (setting) was chosen for the study because of the high (7.1\%) prevalence of HIV and among $12+1$ states which constitute $70 \%$ of Nigeria MTCT burden. She is also home to 12,027 HIV positive pregnant women without which intervention may result in 4,009 preventable cases of paediatric HIV infection $[15,16]$.

\section{Ethical considerations}

The study received ethical approval from the University of Ottawa Research Ethics Board (REB) and the University of Calabar Teaching Hospital Research Ethics Committee. Study participants were provided with study information letter after which they signed informed written consent. The ethical protocol was strictly adhered to throughout the research process. Administrative leads at the various organizations (i.e., embedded units) involved in the study also provided permission to access their facilities at study sites.

\section{Sample and data collection}

Through purposive and snowballing sampling techniques, 30 nursing and other health care leaders were recruited from the various embedded units. To ensure geographical variation and credibility of study findings, participants from each zone (one urban and one rural local government area) were chosen. Recruitment for study was based on study criteria such as participants' knowledge and position occupied in the health care system as well as their involvement in programs affiliated with elimination of mother-to-child HIV transmission in the state. Data sources were semi-structured individual interviews, document reviews, and focus group discussions served as memberchecks and facilitated further data collection.

The interview guide was developed based on the research purpose, objectives and the existing literature on the phenomenon of interest. The interview questions were pilot tested with two nurse's leaders who were not part of the study participants to ensure their relevance. Although no changes were made following the pilot testing, the interview guide continued to evolve as it is often the case in qualitative research. Face to face interviews were conducted with about 27 participants, while 3 participant's interviews were conducted through the telephone with a total of 30 interviews which lasted for about 60 to 90 min each. At the end of each interview, participants were told that if need be, they might be invited to a focus group discussion in the near future to aid in the validation of the study findings. The interview was audio taped. However, only one participant chose not to be recorded and field note was used to capture her story. Extreme difficulty was encountered in scheduling interview with most health care leaders and 2 leaders changed their minds about being interviewed after missing scheduled appointments. Data was transcribed verbatim and analysed using thematic analysis. Trustworthiness of data was ensured through data validation strategies such as triangulation, member-checking, audit trail and prolonged engagement.

\section{Results}

\section{Socio-demographic characteristics of participants}

30 nurses and non-nurses leaders participated in the study (Table 1). Participants were recruited from Ministry of Health, 5 (16.67\%); National Agency in Control of AIDS (NACA), 2(6.7\%); General hospital, Calabar, 3(10.0\%); General Hospital, Ogoja, 2 (6.7\%), health organisations: FHI 360 and (name in full) SOML 2(6.7\%); University of Calabar Teaching Hospital, 5 (16.67\%) and Primary health care centres 9 (30.0\%); and Nursing associations (National Association of Nigeria Nurses and Midwives, NANNM and West African College of Nursing, WACN), 2 (6.7\%). In the area of leadership, majority 25 (83.30\%) were nurse leaders while $5(16.67 \%)$ participants were non-nurse leaders. Majority of the participants were females, 25 (83.30\%) while 5 (16.67\%) were male participants. 17 (56.67\%) participants were between the age range 51 to 60 years.

\section{Major Themes}

Three major themes emerged from the data analysis namely: 1). Limited nurses' involvement in PMTCT policy decision making, 2). Barriers to nurses' contributions in decision-making fora, and 3). 


\begin{tabular}{|c|c|c|}
\hline Variables & Frequency & $\%$ \\
\hline \multicolumn{3}{|l|}{ Practice Area } \\
\hline Ministry of Health & 5 & 16.70 \\
\hline NACA Cross River State & 2 & 6.67 \\
\hline General Hospital, Calabar & 3 & 10.00 \\
\hline Implementing Partners & 2 & 6.67 \\
\hline General Hospital, Ogoja & 2 & 6.67 \\
\hline NANNM & 1 & 3.33 \\
\hline WACN & 1 & 3.33 \\
\hline LGC(PHC) & 9 & 30.00 \\
\hline UCTH, Calabar & 5 & 16.67 \\
\hline \multicolumn{3}{|l|}{ Types of Leaders } \\
\hline Nursing & 25 & 83.30 \\
\hline Other health care leaders & 5 & 16.67 \\
\hline \multicolumn{3}{|l|}{ Sex } \\
\hline Male & 5 & 16.67 \\
\hline Female & 25 & 83.33 \\
\hline \multicolumn{3}{|l|}{ Age Range (years) } \\
\hline $21-30$ & 1 & 3.33 \\
\hline $31-40$ & 3 & 10.00 \\
\hline $41-50$ & 9 & 30.00 \\
\hline $51-60$ & 17 & 56.67 \\
\hline \multicolumn{3}{|c|}{ Highest educational qualification } \\
\hline RN/RM Diploma & 13 & 43.33 \\
\hline Bachelor's Degree & 4 & 13.33 \\
\hline Master's Degree & 3 & 10.00 \\
\hline Doctorate Degree & 5 & 16.67 \\
\hline \multicolumn{3}{|c|}{ Years of Working Experience } \\
\hline $6-10$ & 3 & 10.00 \\
\hline $11-15$ & 5 & 16.67 \\
\hline $15-20$ & 8 & 26.67 \\
\hline 21years and above & 14 & 46.67 \\
\hline
\end{tabular}

NACA: National Agency in Control of AIDS; NANNM: National Association of Nigerian Nurses and Midwives; WACN: West African College of Nursing; LGC: Local Government Council; PHC: Primary Health Care; UCTH: University of Calabar Teaching Hospital

Table 1: Frequency distribution of demographic variables.

Empowerment strategies to improve nurses' contributions in decision making

\section{Limited nurses' involvement in PMTCT policy decision making}

Although all nurse leaders were directly involved in implementing policies pertaining to PMTCT, none of them had any meaningful involvement in the actual policy formulation process. One participant stated, "nurses implement policies, we do not formulate policies". Nurse leaders generally assumed that having nurses directly involved in policy formulation was out of the norm of health care routines. She recalled, "It is not a regular practice to have nurses involved in policy formulation". These opinions are also shared by non-nurse leaders who affirmed that policy formulation was not a role for nurses. "It is enough that nurses are involved in implementing PMTCT policy. What contributions can they make in the federal level in policy formulation." In the same vein, another non-nurse leader added that "although we cannot do without the nursing workforce, but if we must attain our set goals, they are not among the key actors we need in developing PMTCT policies in this state". However, all informants agreed that "all stakeholders are needed in the implementation of policies, but not all are involved in policy formulation process". Overall, most of the participants denied involvement in any form of policy formulation, even with those policies that were not associated with PMTCT. Few nurses affirmed involvement in work place policy as reiterated in this narrative:

Well, I wouldn't say I am heavily involved in policy development, but being a leader, I am not involved [at a] very high policy level. But I am associated with making small policies that regulate the day-to-day activity of this agency. Policy that affects the work itself, you can call it lower level policies.

Nurse leaders were generally aware of how health care policies, including PMTCT, were made: "Formulation of policies is always a flow from top to bottom; what is decided at the national is what the state does". Participants also acknowledged that majority of policies in Nigeria come from the federal government like the federal ministry and send down to the state ministry. A nurse leader affirmed noninvolvement of nurses even at the federal level as reiterated "I am not aware of any nurse being involved at that level of policy". In the words of another nurse leader:

I am not involved in policy development and I can't really say nurses are, because most times, these policies are developed right from the top at the Federal Ministry at national headquarters. They are expected to be implemented at the state level. So those involved in implementing HIV programs just tell us, we have this national policy on this or whatever, organize a workshop, and bring in a non-governmental organization and all that. But the inputs of stakeholders who are really involved in practice or leadership of professional groups are not sought out.

There was a general complacent attitude of nurses towards their non-involvement in policy formulation. Nurse leaders in the various embedded units and those working directly in PMTCT units were reluctant to make waves. They seem to go along with their situation as evident in their acceptance of their non-involvement in PMTCT decision-making as a normal procedure or the status quo. For instance, one nurse stated: "To be precise, we look at how to overcome implementation constraints and not to formulate policy. That role [Policy formulation responsibility] is reserved for Directors, the Permanent Secretary and the Commissioner". Similarly, a nurse leader clearly pointed out that "involvement in policy or non-involvement is not an issue; nurses' priority is their salary, and only very few feel the pain of marginalization from policy formulation". According to this leader "this has been the status quo and change is difficult as nurses fail to realize or seek a position in the health care policy arena". In addition, some nurse leaders justified nursing's position in relation to other professions as evident in this quote from one nurse, "from the inception of the health care system, doctors were the head and nurses were at the background. And it is not every issue [for which] nurses' consent was sought". Similarly, another participant stated:

I am not involved in policy formulation and none of us in this unit is involved although we work in HIV/PMTCT program. We are just told what to do, how to do things, and while we do, there may be some challenges, and the Director brings people who are experienced in that particular area to be part of our meeting. We share ideas, we ask questions, seek clarifications, and based on that, most of the time recommendations are made.

Some nurse leaders generally accepted their present situation for fear of intimidation "Let them run the system the way they like; I do what I can. You know if you raise an alarm you can be transferred to where your voice will never be heard". 


\section{Barriers to nurses' involvement in decision-making}

During the study, all identified barriers were grouped into two categories: individual and systemic. Individual barriers refer to the specific personal characteristics that limit a nurse's ability to be involved in policy formulation, such as lack of awareness and poor educational background. Systemic barriers manifest themselves as problems within organizational structure, system politics, and marginalization of some professions from strategic managerial positions.

Individual barriers: Nurses were not aware of the significance of their contribution to policy with respect to the health care system and patient; therefore, they become aloof with issues associated with policy formulation. This is obvious in the statement of a non-nurse leader who stated: "nurses do not realize the importance of their policy contribution to the community in which they serve". In the same vein other non-nurse's leaders affirmed that "nurses are yet to realise the essence of policy for their profession and that of the patient under their care, if they implement HIV policies, why can't they be proactive during policy development process". In addition, some nurse leaders were of the opinion that nurses lack confidence in their ability to competently participate in decision making for a. For instance, one nurse leader stated: "we are aware of our right to participate in policy development forum, but when you get there what is your contribution". Participants also asserted that poor educational background predisposed nurses to lack of confidence which fuelled their inability to fight for their legitimate rights. Another participant noted: "Our powerlessness can be traced back to our educational status; when we have nothing to offer in such fora; we are barred from participating in future fora".

Systemic barriers: Participants generally accepted that nurse's contribution in the health care system is not really valued. In the words of a non-nurse leader "we don't skew to nurses, when it comes to policy development". Nurse leaders reported on nurses' marginalization and asserted that nurses remained the forgotten voice in many decisionmaking fora. Some noted that occasionally some core decisions were taken for nurses even in their absence. Another nurse leader bemoaned that most stakeholders placed little or no value on what nurses had to contribute, resulting in their marginalization in the health care system: "Some professional groups (nurses) are marginalized in the health care system, their opinion does not matter and other professionals think that they have nothing to offer in policy formulation". A nurse leader in affirming the devaluation of nursing contribution in policy arena questioned: "can you ever imagine a health care policy without a medical doctor? If there is any, I mean the whole committee [would query it]. But nurses can be absent and no eyebrow will be raised". Nurse leaders also affirmed that the undervaluing of nursing contribution in policy arena transcend the various health care facilities in the state and the country as a whole.

The nursing profession in Cross River State and Nigeria is generally undermined, people don't value the nursing profession, because if they [did], in major health decision making, definitely they would want input from nurses, and involve them in decision-making [fora] in the state.

Nurses' leaders also reiterate on constraints with regard to the position of nursing within the organisational structure of the health care system at the local, state and federal levels in the country. At the facility level nursing leaders bemoaned the lack of invitations extended to them: "I have never been invited to any PMTCT policy forum". Not being invited is attributed to nurses not occupying managerial positions, a pre-requisite to being involved in policy making. As one participant noted, "in this local government headquarters no nurse is serving as an administrator or political head in any of the units. So how can we be involved in policy when we can't occupy such posts?"

Study also revealed that, lack of nurse's involvement in politics automatically excluded them from occupying certain strategic positions of authority as well as policy forums as stated: "The highest post we nurse can attain is primary health care coordinators; none of us have ever occupied political posts such as head of local government administrator, Counsellors or Secretary of Council, due to our noninvolvement in politics".

The organizational structure of some establishment keeps nurses and some health professionals on the periphery: "Nurses do not occupy senior management positions in this establishment". Informants and document review revealed the absence of nurses in boards of management and hospital house committees. These committees are dominated by certain professions, and we operate at a low level". Study also revealed that in some health care institutions, only degree holders are allowed into their management meetings, and nursing heads without degree are not invited: "My predecessor was not invited to management meetings because she did not have a degree".

\section{Empowerment strategies to improve nurses' contributions in decision making}

The suggested measures to actively involve nurses in policy formulation include: Creating awareness through nursing associations, promoting inter-professional harmony, promoting higher educational qualifications and building capacity, group advocacy/having nurse leaders who can advocate for nurses, having more nurses occupying managerial positions, having nurses who can mentor others actively in the community, and getting more involved in the health care system politics.

A consensual measure suggested to facilitate nurses' involvement in policy is to create awareness through the use of the nursing association as stated, "our association has a lot to do when it comes to policy. It can enlighten nurses and ginger them into policy arenas". Participants also acknowledged that steps should be taken to create awareness of the need for inter-professional harmony in the health care system, where input from all stakeholders is sought and valued. Participants also emphasized the need for educational advancement to instil competence and self-confidence as stated: "Going into a forum where everyone is educationally advanced can be quite intimidating for someone with a diploma, and she (the nurse) might not be able to contribute intellectually". There was a general consensus for nurse's involvement in health care system politics. "You cannot really take away politics from policies, the two go together," one participant contended. Since politics infiltrate all aspects of health care system, participants reiterated that: "We need nurses to take the lead in political campaigns, so that we vote for them, [and so that we do not always have to vote] for others". Group advocacy to the government through commissioner for health was recommended, "Use of nursing associations provides nurses with a voice in the policy arena".

Additionally, study revealed building of nurses' capacity in policy development to prevent what an informant called "flaws" that illuminate a paucity of knowledge in the field. The need to develop curriculum that integrates policy courses into higher educational programs was recommended. For example, some nurse leaders suggested starting from the training school with a curriculum that is policy sensitive. "This will adequately prepare nurses and sensitize them towards health 
care system policy". Study also revealed that the career trajectory of nursing profession in the Nigerian health care system allows directors of nursing services with opportunities to be involved in management meetings, but most often these experienced nursing directors have few years to their retirement. Therefore, as soon as they learn about how to navigate policy arena, they are retiring from services. In the words of an informant "the best mentors in policy should be nurses and I mean nurses with experience in policy boards, like our retired directors, they can help the younger nurses navigate policy arena". "The retired nursing association group if formed can also be common ground for interaction between old and new nurses".

\section{Discussion and Implications}

Though the Nigerian national HIV policy formulation approach assumed a multi-disciplinary and sectoral slant, there is a salient elimination of nurses from PMTCT policy arena while they remain the main implementers of this policy in their respective practice settings. Their lack of involvement in policy decision making may be attributed to non-recognition of their contribution, or perception of their contribution as irrelevant. Therefore, PMTCT policies developed were imposed on them to implement. However, nurses remain silent and accept their non-involvement as the status quo. A similar situation was reported in Richter et al. who affirmed that nurses were mainly involved in the implementation of HIV/AIDs policies and not policy formulation [17]. The top-down, bottom-up or the in-between approach recommended by WHO is disregarded in this study setting, therefore implementation challenges identified by nurses were not taken into consideration to guide policy formulation [18]. This may adversely affect the systems' ability to attain health related goals in the context of MTCT in HIV in Nigeria. This finding was analogous to Gilson et al. who asserted that nurses were not given the opportunity to provide feedback on how policy impacted on them [19].

Studies from resource-limited countries also affirmed nurse's suboptimal participation in any policies issues including HIV $[2,12,20]$. Richter et al. reported that though nurses were at the forefront of HIV prevention and care in many countries, they had limited involvement in policy decisions and development [17]. The authors further revealed that policies were imposed on nurses: "They were either not allowed to participate in policy development or policies were imposed from the top down" (p.3). Elimination of nurses from policy arena had also been obvious in international organisations such as WHO, where nursing specialists constituted less than $1 \%$ of the committee [21]. However, the findings of this study was also analogous to WHO and Wilson, Whitaker and Whitford who reported that despite nurses' contribution to the health care system, they are not often identified as key stakeholders at every level of the delivery system, that is, from policy formulation to operations $[4,22]$.

This study has identified the major barriers confronting the participants as individual or systemic barrier. These were quite obvious because while attention is focussed on external factors that hinder involvement in policy, individual inherent characteristics also hinder nurse's active participation in policy formulation. The identified barriers were similar to Richter et al. who posited that barriers to nurses' involvement in policy formulation emanate from individual and organizational capacities [17]. These two obstacles occlude nurses' perception beyond the bedside, so that the way policies are generated and reformed are omitted from their primary responsibilities [23].

Individual constraints identified in this study are secondary to nurse's personal evaluation of their skills/knowledge in policy arena, resulting in a general lack of confidence. This is consistent with the report from Abood that most nurses are afraid of leaving their comfort zone (bedside nursing) [13]. Moreover, they felt that their skills in the policy arena were substandard and they gave way to other professionals they presumed were higher than themselves.

This study also identified low educational qualifications as a hindrance to nurses' involvement in policy. Most nurses in this setting have only their diplomas in nursing as their highest educational qualification, while most health establishments and agencies use the first degree as a criterion for invitation to policy arenas or to management meetings. Their low educational qualifications may prevent an effective contribution at the policy table or may generate general feeling of incompetence around other professionals. This finding corresponds with Edwards et al. report that there are very few graduate-prepared nurses in the workforce in low- and middle-income countries, which hinders their engagement in research and policy development [3]. Similarly, Boswell, Cannon, and Miller opined that nurses lack skills as well as resources to develop inherent skills in policy participation [24]. However, according to Phaladze, policy makers assume that nurses lack the expertise and competence to participate in policy formulation; therefore, their contributions were not needed when making major health care decisions [10].

In Nigeria presently, none of the schools of nursing or universities running nursing programs have any policy courses within the diploma or first degree curricula. This finding agrees with Malone and Priest, Seagrott, Green and Rout who asserted that until the past two decades, it was rare to find health policy content included in nursing education or practice expectations $[25,26]$. The lack of policy preparedness in schools produces lack of confidence and poor contributions in the policy arena. This finding is similar to Hofler who stressed that the absence of policy courses in schools predisposes nurses to have little knowledge of policy issues [27]. Similarly, Deschaine and Schaffer also indicated that the lack of baccalaureate and graduate education hindered the development of policy competency among nurses [28]. Strategies to overcome individual constraints is consistent with Taft and Nanna who affirmed that active engagement of nurses in policy could be achieved through divulging how and where health care decisions are made and what triggers the promulgation of new health policies; this awareness exposes the mystery and ambiguity associated with policy making [29]. Studies by some authors also revealed that building capacity in health policy increases self-competence in knowledge, skills, and understanding about activities associated with health care system policy development [30].

The health care system constraint identified in this study clarifies the undervaluing and marginalization of nursing workforce in the study setting. These constraints are subtle power manifestations which are said to be omnipresent, inherent in relationships, and exercised from "innumerable points" [31]. These constraints limit the scope of nursing practice, which requires individual nurses to participate in policy formulation as part of their professional work and to use their power to support and impact health care policy [13,32-35].

The lack of value placed on nurses' opinions pave the way for elimination of nurses from decision making on major policies even with those they are supposed to implement. According to McDonald power underlies and fuels issues pertaining to the devaluing of nurses' contributions and subordinate nurses' knowledge [36]. The author asserted that while viewing nursing as a profession dominated by women, it is also pertinent to note that gendering processes extend beyond individual nurses to include organizations and institutions 
as well as bodies of knowledge. Hence the devaluing of nurses' contribution stem from cultural power arrangements. Edwards et al. also affirmed that this devaluing may emanate from the structure of the health care system which places nurses in subordinate positions and this perception extends into the policy arena [3].

Historically nursing has suffered from a poor public image that has been difficult to eradicate, and their influence in the policy arena has remained low compared to other professions [11]. In the same vein, Holmes and Gastaldo asserted that traditionally, nurses have been depicted by others, as a powerless professional group without social prestige; therefore, their contributions in policy are not valued [37]. However, Benner et al. provided a more holistic view for policy barriers encountered by nurses as emanating from societal, institutional, and workplace cultures [38]. In the study setting, institutional and workplace regulations eliminate nurses from policy formulation and society fails to question their absence. This finding is similar to Sharif who admitted that the public image of nursing determines how society will value nurses' input and the demand for their contributions in policy decision making [11].

Exclusion of nurses from some high administrative post, places the nursing workforce in a subordinate/powerless position, implementing the orders of their superiors. This is consistent with Gaventa and Pettit view that power dynamics hinder some professionals from occupying key positions in the health system [39]. Furthermore, Weber affirmed that offices or positions within the bureaucracy are organized into a hierarchical system, where some have more power than others. Moreover, power is associated with the position and not the individual [40]. However, the World Health Assembly encouraged all director generals "to strengthen WHO's capacity for development and effective implementation by the appointment of professional nurses and midwives to specialist posts in the Secretariat both at headquarters and in regions" [41]. In spite this recommendation, this study revealed that in the Cross River State health care system, no nurse has ever served as a Commissioner for Health or Permanent Secretary in the past two decades. The prevention of some professionals from being eligible for certain posts is a conscious act to eliminate some professionals from the decision-making process. Edwards et al. also affirmed that hierarchies of power exist among health disciplines that persistently present a serious barrier to nurses' involvement in policy, since most nurses do not assume key positions [3]. A similar situation was reported by Ditlopo et al., in that the nurses' position in the health system hierarchy hinders their input in health policy fora and may as well prevent the bottom-top policy contribution which enhances the identification of implementation challenges [12,17].

Study revealed lack of invitations to the policy formulation arena as a barrier. This is true because nurses do not occupy position to be on the lead, but to be led by others, therefore should wait for invitation. This is consistent with Richter et al. opinion that: "frontline nurses were often not consulted prior to the implementation of a new policy and it was assumed that they would willingly agree to implement it" [17]. Abood asserted that nurses remain in the background and wait to be added as an afterthought to the policy and legislative arenas instead of being involved in the planning and executions of health policies [13].

This study found that most nurses were not interested in health care system politics; therefore, their non-involvement further dampened their engagement in policy development. In Nigeria, the political arena is dominated by men and this stance criss-cross into the nursing profession and influences nurses' attitude towards politics at work. This cultural believe about gender and political engagement contributes to nurses' (who are mostly female) lack of interest in politics. Similar studies have also acknowledged the limited involvement of nurses in health policy, their lack of political awareness, political participation, or political activism $[24,42,43]$.

Cristian affirmed that political ideologies impose an influence in the ways health care systems are organized and function [44]. Policy makers rely on the political process to determine an acceptable course of action for individuals with contradictory proposals, demands and values [45]. This study finding is in contrast to Sharif's report, that nurses in East Africa demonstrated some degree of political engagement although their participation in actual policy development was limited [11]. Studies in the USA have also demonstrated nurses' active engagement in politics with the ultimate purpose of influencing government policies $[46,47]$. Although there are various levels of political engagement in different countries, some studies doubt the ability of nursing political movement ever influencing government policies $[11,48]$. However, it is important to note that politics and policy go hand in hand and to have an impact on health policies, nurses need to be engaged in politics, which provides the powerbase to know where and when to exert influence $[13,45]$.

\section{Identified facilitators to decision making}

In order to actively engage nurses in policy development, both individual and health care system constraints must be overcome through identified strategies such as building policy capacity, mentoring, group advocacy and organizational restructuring.

Building policy capacity is imperative if nurses are expected to make substantial contributions in the policy arena. It is obvious that nurses' preliminary training in their various schools of nursing did not equip them significantly to engage in policy activities. Many authors have supported building policy capacity as a panacea for nurses in lowand middle-income countries $[2,3,13,25,26]$. In upholding the need to build nurses capacity, Abood and Gaventa and Barrett, emphasized that possessing the knowledge and skill that is needed in a particular situation is referred to as expert power, which provides nurses with considerable credibility to speak out on health care issues $[13,49]$.

The need for policy mentors to enhance nurses' personal and professional skills in health care reforms is imperative because without mentor's nurses would never gain the skills and confidence to navigate policy arena. This is line with Habermas who noted that the ruled should be given adequate opportunity to acquire the skills of discourse to enhance their participation in issues affecting them [50]. The finding also substantiates Allen et al. who agreed that mentoring enhances career progression, and provides the mentee with a sense of professional identity and self-competence [51]. This finding was similar to Sharif who stressed that supportive mentorship and role modeling enhanced knowledge and skills in policy development activities [11].

Mentoring also provided the leadership to navigate the policy arena and such mentoring activities should be provided at every stage of the policy process, especially where the mentees experiences are limited $[3,13]$. Abood added that such mentors should possess transformational leadership traits that can help mentees to become self-advocates in their prospective settings [13]. In affirmation, Gifford et al. stated that leadership is an essential tool in motivating nurses to use research evidence in clinical practice decision-making [52].

Group advocacy is another envisioned solution to nurses' involvement in policy formulation. This is imperative because lone voices can do little. Studies in many countries suggest that professional nursing associations are the platforms through which nurses' voices can 
be heard [53-56]. Similarly, Abood and Carnegie and Kiger asserted that it is essential for nurses to gain confidence in collective action to take on some form of advocacy to bring about change in the current policies, laws, or regulations that govern the larger health care system $[13,45]$. Gaventa and Cornwall also affirm that participatory/collective group action is necessary to create critical consciousness rising on the visible and invisible power interplays in any organization [57]. Such interplay of power keeps nurses in silent agreement to situations of glaring inequalities. Therefore, collective group action is necessary for liberation from any oppressive health system situation.

Active engagement in politics was also identified as an envisioned remedy to navigate the policy arena. This is true because policies are embedded in politics and according to Longest political interplay precedes actual decision making in policy arenas [58]. Gaventa and Barrett contended that in any organization, what is termed democracy is not really democratic, as political manoeuvring behind-the-scenes occurs [49]. These tactics happen in all health issues as they pass through phases of the policy process; each process is swayed by preferences and influences of factions that view the issue with diverse and competing interests, therefore each faction must understand and engage in political interplay for success $[13,45]$.

The restructuring of organizations is often seen as a solution to unequal opportunities: Taft and Nanna argued that to overcome professional power differentials that hinder nurses' involvement in policy at all levels of health care system, nurses need key individuals in strategic positions [29]. Ditlopo et al. agreed that the health hierarchy and organizational structures in South Africa should be restructured to create a supportive organization that allowed nurses to become the Chief Nursing Officer or Nursing Director in the National Department of Health, as well as a head of the human resource division [12]. Buse, Mays and Walt also suggested the need for such organizational restructuring in New York to allow other health professionals to serve as health ministers [59] while Shariff and Potgieter also saw the same need in Kenya, Uganda and Tanzania [60].

\section{Implication of study}

In view of the centrality of nursing profession, elimination of nurses from health care system policy formulation has prevented nursingrelevant input into policy issues to overcome PMTCT implementation constraints. This also may hinder and contribute to the countries inability to eliminate mother to child HIV transmission

\section{Conclusion}

The unique contribution of nurses in ameliorating the disease burden associated with MTCT in HIV is unquestionable, since transforming the health care system requires the unique contribution of all stakeholders. These contributions include active involvement in every stage policy development process. International Center for AIDs care and Treatment Programs (2013) agreed that creating an HIV-free generation will never be possible without the contribution of nurses and midwives. The Nigerian health system presents major obstacles which hinders nurse's ability to influence and direct policies. To overcome these barriers, there is need to develop a broad-based educational curriculum which will incorporate strategies to build nurses capacity for leadership and policy development in training schools. A transformative nursing leadership and support of the Nigeria nursing association becomes imperative, in order to enhance policy capacity building, mentoring, group advocacy and organizational restructuring. This will enhance nurse's ability to exert both direct and indirect influence to achieve health care system goals.

\section{References}

1. Sturke R, Harmston C, Simonds RJ, Mofenson LM, Siberry Gk, et al. (2014) A multi-disciplinary approach to implementation science: The NIH-PEPFAR PMTCT implementation science. J Acquir Immune Defic Syndr 67: S163-S167.

2. Asuquo E, Etowa J, John M, NdiokA, Sampson-Akpan P, et al. (2013) Assessing nurses' capacity for health research and policy engagement in Nigeria. Journal of Applied Medical Sciences 2: 35-51.

3. Edwards N, Webber J, Mill J, Kahwa E, Roelofs S (2009) Building capacity for nurse-led research. Int Nurs Rev 56: 88-94.

4. WHO (2010) strategic directions for strengthening nursing and midwifery services 2011-2015.

5. International Center for AIDs care and Treatment Programs (2013) Nurses and Midwives: The Frontline against HIVIAIDS. How ICAP is Building Nursing and Midwifery Capacity and Strengthening Health Systems. The Health Workforce Crisis in Sub-Saharan Africa.

6. De Cock KM, El-Sadr WM, Ghebreyesus TA (2011) Game changers: why did the scale-up of HIV treatment work despite weak health systems? J Acquir Immune Defic Syndr 57 Suppl 2: S61-63.

7. Palen J, El-Sadr W, Phoya A, Imtiaz R, Einterz R, et al. (2012): PEPFAR, Health system strengthening, and promoting sustainability and country ownership. $J$ Acquir Immune Defic Syndr 60: S113-S119.

8. WHO, PEPFAR, UNAIDS (2007) Task shifting rational redistribution of tasks among health workforce teams: Global recommendation and guidelines. Geneva: World Health Organization.

9. John I (2014) The War on HIVIAIDS; Impact on demography and the economy.

10. Phaladze A (2003) The role of nurses in the human immunodeficiency virus/acquired immune deficiency syndrome policy process in Botswana. International Nursing Review 50: 22-33.

11. Shariff N (2014) Factors that act as facilitators and barriers to nurse leaders' participation in health policy development. BMC Nursing 13: 20

12. Ditlopo P, Blaauw D, Penn-Kekana L, Rispel L (2014) Transforming nursing in South Africa: Contestations and complexities of nurses' participation in policymaking in South Africa. Glob Health Action 7: 25327.

13. Abood S (2007) Influencing health care in the legislative arena. Online $\mathrm{J}$ Issues Nurs 12: 3.

14. Ugochukwu C, Uys L, Karani A, Okoronkwo I, Diop B (2013) Roles of nurses in Sub-Saharan African region. International Journal of Nursing and Midwifery 5: 117-131.

15. Cross River State Ministry of Health and FHI 360 (2013) State-wide Rapid Health Facility Assessment. Nigeria: Cross River State Ministry of Health and $\mathrm{FHI} 360$.

16. Federal Ministry of Health Nigeria (2011) National standard operating procedures for prevention of mother to child transmission (PMTCT) of HIV. Federal Ministry of Health, Abuja.

17. Richter S, Mill J, Muller R, Kahwa E, Etowa J, et al. (2012) Nurses' engagement in AIDS policy development. International Nursing Review 60: 52-58.

18. WHO (2006) Antiretroviral drugs for treating pregnant women and preventing HIV infection in infants: Towards universal access. Recommendations for a public health approach, WHO.

19. Gilson L, Erasmus E, Kamuzora P, Mathews V, Ngulube TJ, et al. (2006) Applying policy analysis in tackling health-equity related implementation gaps. Equinet discussion paper number 28.

20. Evans C, Ndirangu E (2009) The nursing implications of routine providerinitiated HIV testing and counselling in sub-Saharan Africa: a critical review of new policy guidance from WHO/UNAIDS. Int J Nurs Stud 46: 723-731.

21. Davis Sheila (2012) Why nurses are the unsung heroes of global health. The Huffington Post.

22. Wilson A, Whitaker N, Whitford D (2012) Rising to the challenge of health care reform with entrepreneurial and intrapreneurial nursing initiatives. Online Journal of Issues in Nursing 17: 5.

23. Hewison A (2008) Evidence-based policy: implications for nursing and policy involvement. Policy Polit Nurs Pract 9: 288-298. 
Citation: Asuquo EF, Etowa JB, Gifford WA, Holmes D (2016) Nurses' Involvement in HIV Policy Formulation in Nigerian Health Care System. J AIDS Clin Res 7: 589. doi:10.4172/2155-6113.1000589

24. Boswell C, Cannon S, Miller J (2005) Nurses' political involvement: Responsibility versus privilege. Journal of Professional Nursing 21: 5-8.

25. Malone RE (2005) Assessing the policy environment. Policy Polit Nurs Pract 6: 135-143.

26. Segrott J, Mclvor M, Green B (2006) Challenges and strategies in developing nursing research capacity: A review of the literature. International Journal of Nursing Studies 43: 637-651.

27. Hofler LD (2006) Learning from the best: The benefits of a structured health policy fellowship in developing nursing health policy leaders. Policy, Politics \& Nursing Practice 7: 110-113.

28. Deschaine J, Schaffe M (2003) Strengthening the role of public health nurse leaders in policy development. Policy, Politics \& Nursing Practice 4: 266-274.

29. Taft SH, Nanna KM (2008) What are the sources of health policy that influence nursing practice? Policy Polit Nurs Pract 9: 274-287.

30. Byrd ME, Costello J, Gremel K, Schwager J, Blanchette L, et al. (2012) Political astuteness of baccalaureate nursing students following an active learning experience in health policy. Public Health Nursing 29: 433-443.

31. Foucault M (1980) Power/knowledge: Selected interviews and other writings 1972-1977 (COLIN GORDON Ed.) Pantheon Books, New York.

32. About ANA (2012) American Nurses Association.

33. Barclay L (2010) Nurses should play greater role in health policy planning, management. Medscape: Multispecialty.

34. National Association of Nigerian Nurses and Midwives (2014) The constitution of the national association of Nigerian nurses and midwives.

35. Pan American Health Organization (2004) Nursing and midwifery services contributing to equity, access, coverage, quality and sustainability in the health services. Mid-term plan, Washington.

36. McDonald C (2010) Issues of gender and power: The significance attributed to nurses' work. Realities of Canadian nursing: Professional, practice and power issues (3rd edn) Wolters Kluwer, Philadelphia.

37. Holmes D, Gastaldo D (2002) Nursing as means of governmentality. J Adv Nurs 38: $557-565$

38. Benner P, Tanner C, Chesla C (2009) Expertise in nursing practice. Caring, clinical judgment \& ethics (2nd edn) Springer, New York.

39. Gaventa J, Pettit J (2011) Strategies and forms of power. Powercube.

40. Weber M (1978) Economy and society: An outline of interpretive sociology (G Roth \& C Wittich Edn) University of California Press, Berkeley.

41. World Health Assembly (2011) Strengthening nursing and midwifery. The Sixtyfourth World Health Assembly.

42. Catallo C, Spalding K, Haghiri-Vijeh R (2014) Nursing professional organizations: What are they doing to engage nurses in health policy? Sage Open Journal.
43. Spenceley SM, Reutter L, Allen MN (2006) The road less traveled: nursing advocacy at the policy level. Policy Polit Nurs Pract 7: 180-194.

44. Cristian S (2010) Health systems and the influence of political ideologies Management in Health 14: 4-6.

45. Carnegie E, Kiger A (2009) Being and doing politics: An outdated model or 21st century reality? Journal of Advanced Nursing 65: 1976-1984.

46. Gesse T (1991) Political participation behaviors of nurse-midwives. J Nurse Midwifery 36: 184-191.

47. Ryan-Nicholls KD (2004) Impact of health reform on registered psychiatric nursing practice. Journal of Psychiatric Mental Health Nursing 11: 644-653.

48. Chan W, Cheng B (1999) Political participation in Hong Kong: A study. Journa of Nursing Management 7: 167-175.

49. Gaventa J, Barrett G (2010) So what difference does it make? Mapping the outcomes of citizen engagement. Institute of Development Studies Working Paper 2010: 347.

50. Habermas J (1978) Knowledge and human interest (2nd edn) Heinemann, London.

51. Allen TD, Eby LT, Poteet ML, Lentz E, Lima L (2004) Career benefits associated with mentoring for protégeé: a meta-analysis. J Appl Psychol 89: 127-136.

52. Gifford W, Davies B, Graham I, Tourangeau A, Woodend K, et al. (2012) Developing leadership capacity for guideline use: A pilot cluster randomized control trial. World Views on Evidence-Based Nursing 10: 51-65.

53. Benton D (2012) Advocating globally to shape policy and strengthen nursing's influence. Online Journal of Issues in Nursing 17: 5.

54. MacDonald JA, Edwards N, Davies B, Marck P, Guernsey JR (2012) Priority setting and policy advocacy by nursing associations: a scoping review and implications using a socio-ecological whole systems lens. Health Policy. 107 $31-43$.

55. Matthews JH (2012) Role of professional organizations in advocating for the nursing profession. Online $\mathrm{J}$ Issues Nurs 17: 3.

56. Vandenhouten CL, Malakar CL, Kubsch S, Block DE, Gallagher-Lepak S (2011) Political participation of registered nurses. Policy Polit Nurs Pract 12: 159-167.

57. Gaventa J, Cornwall A (2001) Power and knowledge. Handbook of action research: Participative inquiry and practice ( $P$ Reason \& $H$ Bradbury Edn.) Sage Publications, London, 70-80.

58. Longest B (2006) Health policymaking in the United State. Chicago Health Administration Press (4th edn) Washington, DC.

59. Buse K, Mays N, Walt G (2012) Making health policy (2ndedn) McGraw Hill, New York.

60. Shariff N, Potgieter E (2012) Extent of East-african nurse leaders' participation in health policy development. Nurs Res Pract 2012: 504697. 